\section{Rotura y migración de catéter de reservorio venoso subcutáneo}

\section{Sr. Editor:}

A propósito del artículo publicado en esta revista "Experiencia clínica con reservorios venosos subcutáneos en pacientes oncológicos" por Cózar Ibánez et al, hemos revisado las complicaciones relacionadas con el empleo de reservorios venosos subcutáneos (RVS) en nuestro centro. La necesidad de efectuar tratamientos por vía venosa central hace que la utilización de RVS se haya convertido en una práctica rutinaria en los pacientes oncológicos. A pesar de ello, dichas técnicas no están libres de complicaciones, algunas de ellas graves, y que en ocasiones pueden deberse a defectos en la técnica de inserción del catéter o del propio reservorio.

La rotura y migración de catéter de RVS es una complicación potencialmente peligrosa, cuya incidencia se estima entre el $0,1 \%$ y el $1 \%$ de los catéteres. La causa principal suele ser la fricción mecánica del catéter venoso central a su paso por el espacio costoclavicular. Una vez roto el catéter, el fragmento distal puede migrar a cavidades cardiacas derechas o arteria pulmonar.

En nuestro centro, se han recogido 4 casos en los últimos dos años, lo que supone una incidencia del 1,7\%. Los pacientes eran dos mujeres de 62 y 63 anos, diagnosticadas de carcinoma ductal infiltrante de mama y de adenocarcinoma de ovario, respectivamente, y dos hombres de 56 y 37 anos ambos diagnosticados de adenocarcinoma de recto. En todos ellos el reservorio fue implantado tras recaída de la enfermedad para iniciar tratamiento con quimioterapia y el acceso se había hecho por vía subclavia derecha.

El tiempo medio desde la inserción del catéter a la fractura fue de 19 meses, aunque existen casos descritos a la tercera semana de la colocación.

En dos de los casos, el diagnóstico fue casual, a través de radiograifías de tórax de control, permaneciendo los pacientes asintomáticos, y en los dos casos restantes, los pacientes presentaban clínica de tos seca o dolor en la región del reservorio.

La localización del catéter migrado fue en la arteria pulmonar izquierda. En tres de ellos la extracción se realizó con éxito mediante catéter-lazo por vía femoral o subclavia derecha, mientras que en uno de los casos los intentos de retirar el catéter fueron infructuosos. A pesar de la imposibilidad de extraer el catéter, el paciente permanece asintomático. Se procedió en todos los pacientes a la implantación de un nuevo RIV sin complicaciones.

Isabel Ruiz Martín, Raquel Salazar Sáez y Germán Marcos García Universitario. Salamanca. España

\section{Doble identidad, revistas médicas y MEDLINE}

Sr. Editor:

En el apartado presentación y estructura de los trabajos de las Normas de Publicación de Revista de Oncología se puede leer "en la primera página del artículo se indicarán, en el orden que aquí se cita, los siguientes datos: título del artículo (en castellano y en inglés), nombre completo y apellidos de los autores, centro de trabajo y dirección completa del mismo, título reducido, dirección postal y telefax y dirección de correo electrónico, y otras especificaciones cuando se considere necesario" (Revista de Oncología, normas para autores).

Uno de los requisitos necesita un comentario individualizado: el que estipula nombre y apelidos de los autores. Solicitar los dos apellidos es una particularidad de Revista de Oncología. Otra revista médica, que publica la misma editorial (Doyma) tiene el siguiente requisito, levemente distinto: nombre completo y uno - los dos apellidos de los autores (Medicina Clínica, normas para autores).

La decisión sobre "uno o dos apellidos" debe tomarla cualquier investigador médico muy al inicio de su carrera, puesto que esa decisión tiene un impacto en el sistema de indexación más comúnmente utilizado por la comunidad científica, MEDLINE. Cualquiera que haya firmado artículos médicos puede hacer la prueba de escribir en Pubmed (http://w w w.ncbi.nlm.nih.gov/entrez/query.fcgi ?db =PubMed) su apellido seguido de su inicial, o bien sus dos apellidos seguidos de su inicial. Podrá ver que se llegan a dos resultados distintos y que, por tanto, a efectos de MEDLINE consta como dos personas separadas.

Algunos autores toman la decisión de firmar sus artículos con sus dos apellidos (con o sin guión), y en estos casos no existe esta duplicidad de indexación.

Por tanto, la decisión de firmar los artículos con dos apellidos, como se exige en Revista de Oncología, puede tener un impacto sobre la indexación individual de sus autores y, en algunos casos este impacto puede dar como resultado una "doble identidad".

Creo que es importante que el Comité Editorial de Revista de Oncología modifique sus normas de publicación y que deje abierta la opción de firmar las contribuciones científicas con uno o dos apellidos. Además debería hacer constar explícitamente que esta decisión afectará en el futuro la indexación del autor en algunos servicios de búsqueda blbliográfica como MEDLINE. 